\title{
Fabrication and Evaluation of Two-Junction Carbon Thin Film Photovoltaic Devices
}

\author{
Hisato Kato*, Yuki Yamamoto, Shinya Kato, Naoki Kishi and Tetsuo Soga \\ Department of Electrical and Mechanical Engineering, Nagoya Institute of Technology, Gokiso, Showa, \\ Nagoya 466-8555, Japan
}

\begin{abstract}
In this work, we have fabricated the two-junction carbon photovoltaic devices which consisted of Al/fullerene $\left(\mathrm{C}_{60}\right) / a m o r p h o u s$ carbon $(\mathrm{a}-\mathrm{C}) / \mathrm{C}_{60} / \mathrm{a}-\mathrm{C} / \mathrm{ITO}$ glass structure. We also investigated their photovoltaic properties with the same bandgap and without involving the tunnel-connect layer. We found that the open-circuit voltage in the two-junction photovoltaic device almost doubled compared to the single-junction type and it confirmed that the tandem structure was successfully formed without any tunnel-junction although short-circuit current in the two-junction tended to decrease greatly in comparison to single-junction. Moreover, we studied the effect of film thickness of each film on the photovoltaic properties of two-junction carbon photovoltaic devices and as a result, there was a dependence of film thickness on the photovoltaic performance in the two-junction type. Thus, it can be concluded that the film thickness is one of the significant influences to enhance the photovoltaic performances and our results might be an important approach for fabricating the higher efficiency of two-junction carbon thin film photovoltaic devices made of different band gap.
\end{abstract}

Keywords: Photovoltaic, Carbon, Amorphous, Fullerene, Two-junction.

\section{INTRODUCTION}

Silicon ( $\mathrm{Si}$ ) has been studied as the common solar cell materials for more than six decades since the 1950 's because the energy which is obtained by solar cells using $\mathrm{Si}$ can be an alternative energy to replace fossil fuels [1, 2]. However, there is a problem in terms of cost to realize the higher power conversion efficiency and purity of $\mathrm{Si}$. Therefore, some of inorganic materials such as CIGS, GaAs, CdTe, CdS and others have been developed as substitute materials in order to reduce the cost of solar cell production [3-5]. In addition, dye-sensitized solar cells [6], organic solar cells [7] using organic materials, and recently, perovskite solar cells [8] have attracted attention as the next generation solar cell due to their low cost although those solar cells have some problems related to their stability and efficiency.

In recent years, carbon has exhibited the great performance owing to its various outstanding properties for solar cell application since Prof. Sharon et al have reported the pioneer work on carbon solar cell in 1997 [9-11]. To date, among various carbon materials, such as fullerene [12], carbon nanotube (CNT) [13], graphene [14] and amorphous carbon (a-C) [15] have been implemented as basic materials for organic solar cell. In the case of a-C, this material is considered to be an attractive material because it is easy to deposit in

*Address correspondence to this author at the Department of Electrical and Mechanical Engineering, Nagoya Institute of Technology, Gokiso, Showa, Nagoya 466-8555, Japan; Tel: +81-52-735-5532;

Fax: +81-52-735-7120; Email: h.kato.159@nitech.jp large area and its band gap can be adjusted by changing the growth condition [16, 17]. However, the structural control and impurity doping of a-C for attaining the higher power conversion efficiency is still challenging.

The authors reported a-C/ $\mathrm{C}_{60}$ all-carbon photovoltaic devices in 2013 [18] by using the nature that a-C is p-type [19] and $C_{60}$ is n-type [20]. In addition, the a-C preparation was conducted by remote plasma cracking of $\mathrm{C}_{60}$ in our group. Since the a-C film and $\mathrm{C}_{60}$ film have the weak character of $p$-type and $n$ type semiconductor respectively [21, 22], we investigated the single-junction carbon thin film photovoltaic device. Very recently, the effect of sublimation temperature on the photovoltaic properties of $\mathrm{C}_{60} / \mathrm{a}-\mathrm{C}$ device was reported by our group [23]. So far, the single-junction photovoltaic device showed the low power conversion efficiency and concerning to the previous experiment, we tried to achieve the better carbon photovoltaic device performance by device structure modification. In this study, we noticed that a method which can be utilized for improving the power conversion efficiency of organic photovoltaic device is by arranging the two-junction structure (tandem structure). We considered that this method can improve the power conversion efficiency of device by joining photovoltaic devices with different bandgap. Since it is possible to tune the band gap by changing the growth conditions, using $\mathrm{a}-\mathrm{C}$ which is suitable for photovoltaic device fabrication with different band gap can be attempted for organic photovoltaic application. To the best of our knowledge, there is no report about the investigation of fullerene/a-C for tandem photovoltaic 
device application. Therefore, in this paper, we report the fabrication of two-junction carbon thin film photovoltaic devices with same the bandgap as a preliminary step for achieving the two-junction for the first time, focusing on the effect of film thickness of each film on the photovoltaic properties of two-junction carbon photovoltaic devices.

\section{EXPERIMENTAL}

In this study, the samples were prepared by the deposition of $\mathrm{p}$-type a-C and n-type $\mathrm{C}_{60}$ on ITO glass substrate using ultra-high vacuum chamber (UHVC) with the base pressure at $10^{-8}$ Torr and followed by the deposition of $\mathrm{Al}$ electrode. The $\mathrm{a}-\mathrm{C}$ thin films were deposited on ITO glass substrate by exposing $\mathrm{N}_{2}$ radical to sublimate $\mathrm{C}_{60}(99.5 \%)$ in the UHVC. Our deposition system consists of $\mathrm{C}_{60}$ Knudsen cell, $\mathrm{N}_{2}$ radical cell, turbo molecular pump (TMP), load-lock chamber, and others which do not include the substrate heater. Moreover, the rf power, the rf frequency and $\mathrm{N}_{2}$ flow rate were $300 \mathrm{~W}, 13.56 \mathrm{MHz}$ and $1.5 \mathrm{sccm}$, respectively. The pressure during the deposition of a-C was 1.1-1.3 $\times 10^{-4}$ Torr, and the sublimation temperature of $\mathrm{C}_{60}$ was $500{ }^{\circ} \mathrm{C}$. The UHVC system is same as reported in ref.18. Regarding the $\mathrm{C}_{60}$ thin films, it was deposited on the $\mathrm{a}-\mathrm{C}$ thin film by sublimating $\mathrm{C}_{60}$ at $500{ }^{\circ} \mathrm{C}$ using the same equipment. The pressure during deposition was 2.0-2.8 $\times 10^{-7}$ Torr. Regarding the Al electrode preparation, it was arranged by resistance heating method using other vacuum deposition equipment. The degree of vacuum at that time was about $3.0 \times 10^{-4} \mathrm{~Pa}$.

In order to evaluate the performance of a-C and $\mathrm{C}_{60}$ in this work, both $\mathrm{a}-\mathrm{C} / \mathrm{C}_{60}$ single-junction and twojunction photovoltaic devices were prepared separately, then, the performance of these samples was compared. A schematic view of the fabricated single-junction and two-junction photovoltaic devices is shown in Figure 1. Based on the Figure 1, our singlejunction was composed by $100 \mathrm{~nm}$ of a-C and $50 \mathrm{~nm}$ of

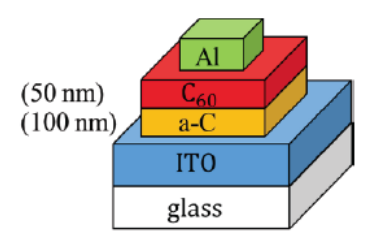

Single-junction

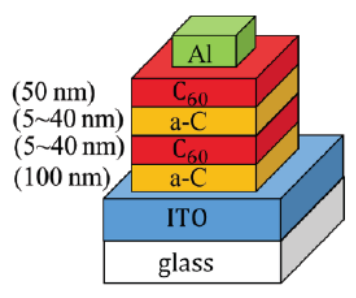

Two-junction
Figure 1: Schematic illustration of carbon thin film photovoltaic devices.
$\mathrm{C}_{60}$ which was considered as the basic structure, and to make the two-junction film, $\mathrm{C}_{60}$ and $\mathrm{a}-\mathrm{C}$ were sequentially added between a-C and $C_{60}$ basic structure. In addition, the film thickness of those inserted films was varied from $5 \mathrm{~nm}$ to $40 \mathrm{~nm}$. Furthermore, the effect of film thickness was investigated.

For evaluating our samples, the current densityvoltage $(\mathrm{J}-\mathrm{V})$ characteristics were measured under standard light of AM 1.5 illumination with $0.09 \mathrm{~cm}^{2}$ of active area measurement and the photovoltaic parameters such as open circuit voltage $\left(V_{O C}\right)$, short circuit current density $\left(J_{S C}\right)$, fill factor $(\mathrm{FF})$ and power conversion efficiency (PCE) were calculated from the $\mathrm{J}$ $\mathrm{V}$ curves. Moreover, samples were also characterized by cross-sectional transmission electron microscopy (TEM), ultraviolet-visible (UV-Vis) absorption spectroscopy and Raman spectroscopy using a laser with a wavelength of $532 \mathrm{~nm}$.

\section{RESULT AND DISCUSSION}

\subsection{Cross-Sectional TEM}

In order to confirm whether a-C film and $\mathrm{C}_{60}$ film were deposited with the expected film thickness, the cross-sectional TEM images of prepared singlejunction with $100 \mathrm{~nm}$ of a-C and $50 \mathrm{~nm}$ of $\mathrm{C}_{60}$ and twojunction with $100 \mathrm{~nm}$ of a-C, $20 \mathrm{~nm}$ of $\mathrm{C}_{60}, 20 \mathrm{~nm}$ of a$\mathrm{C}$ and $50 \mathrm{~nm}$ of $\mathrm{C}_{60}$ were taken and these are shown in Figure 2. Although Al is formed as an electrode in our photovoltaic devices, for TEM measurement, Au was deposited on the surface of the film for protection.

From Figure 2, since it was possible to confirm the boundary between $\mathrm{C}_{60}$ and $\mathrm{a}-\mathrm{C}$ as shown by the arrows, it was found that the film was formed with the expected thickness. Organic materials are susceptible to changes in state due to damage by electron beams received during processing or observation. Therefore, it was difficult to observe a lattice of $\mathrm{C}_{60}$ clearly because the observation target are organic materials.

\subsection{Raman Spectroscopy}

In order to confirm whether prepared samples were composed of $\mathrm{C}_{60}$ and $\mathrm{a}-\mathrm{C}$ as expected, samples which consisted of each single layer film of a-C and $\mathrm{C}_{60}$, a$\mathrm{C} / \mathrm{C}_{60}$ single-junction and two-junction were evaluated using Raman spectroscopy. In this analysis, we only applied the sample as described in the Figure 1 excluding the $\mathrm{Al}$ electrode. 


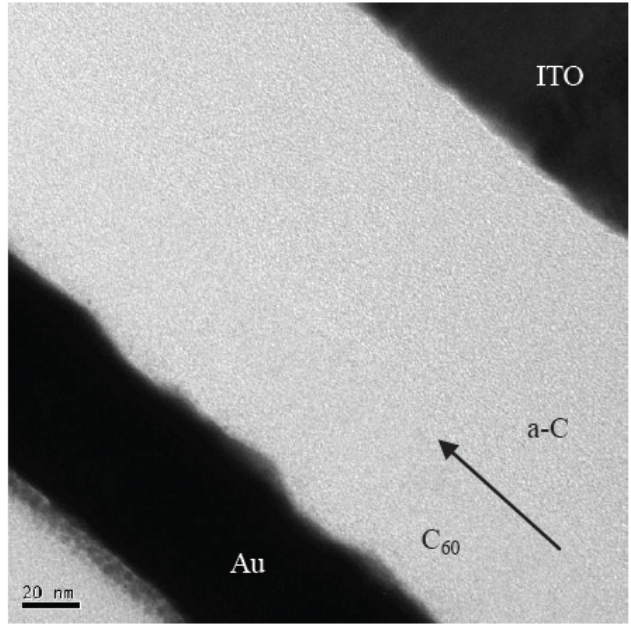

Single-junction

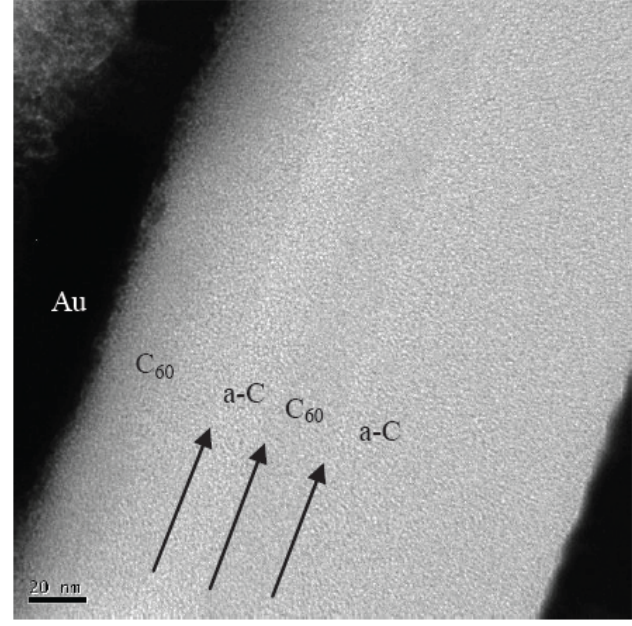

Two-junction

Figure 2: Cross-sectional TEM images of single-junction and two-junction photovoltaic devices.

Figure 3 shows the Raman spectra of singlejunction and two-junction carbon photovoltaic device with different layer thickness. Figure $\mathbf{3}$ also includes the Raman spectrum of ITO glass which was being as the sample substrate. The intensity was normalized in each sample. In the Raman spectra for single layer film which contained $\mathrm{C}_{60}$, there are some peaks around $1427 \mathrm{~cm}^{-1}, 1460 \mathrm{~cm}^{-1}$ and $1567 \mathrm{~cm}^{-1}$, also, in the single layer film which was composed by a-C, the broad peaks are observed around $1380 \mathrm{~cm}^{-1}$ and $1574 \mathrm{~cm}^{-1}$. These results are in line with the literature value [24, $25,26]$. For the film which consisted of $\mathrm{C}_{60}$ and a-C, the combination of peak from each single layer film was observed in the Raman spectra. In this data, we found the slight change in peak intensity ratio in the samples due to the different numbers of junction and different thickness although we applied the same growth condition for all of samples. Therefore, there is a high possibility that unevenness of deposition exists in the sample. Moreover, during the film deposition process, it might be possible that the substrate temperature rose and it changed the film state due to the different $a-C$ circumstance.

In the a-C single layer spectrum, it is known that the intensity ratio $\left(I_{D} / I_{G}\right)$ of the D-peak (broad peak around $1380 \mathrm{~cm}^{-1}$ ) and the G-peak (broad peak around 1574 $\mathrm{cm}^{-1}$ ) relates to the cluster-size of $\mathrm{sp}^{2}$ carbon and it has been reported that the resistivity decreases along with an increase of size [25]. We applied this formula to determine the $I_{D} / I_{G}$ ratio which is shown in the Figure 3 although our calculation was not only for a single layer film of a-C. The values of Raman peak of each sample and their ratios are shown in Table 1. As a result, it was found that the peak intensity ratio of each sample is almost the same. Therefore, we concluded that it is unnecessary to consider the difference in resistance between each sample due to the difference in the state of a-C.

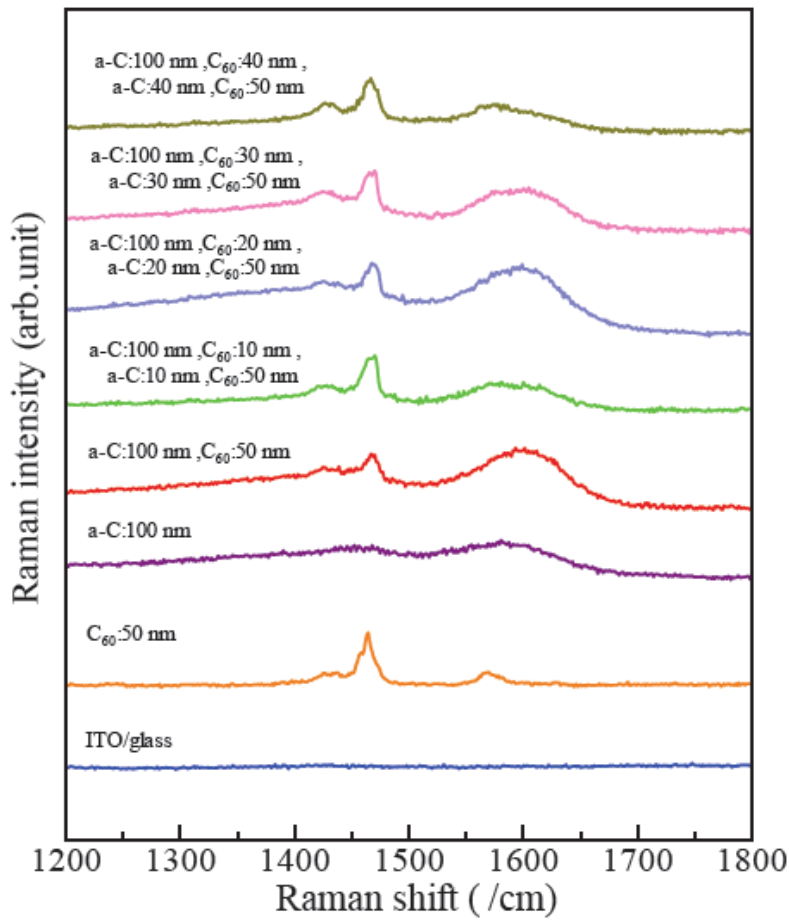

Figure 3: Raman spectra of carbon photovoltaic devices with different structures.

\subsection{UV-Vis Absorption Spectroscopy}

In order to confirm absorption of prepared samples, samples which consisted of each single layer film of a$\mathrm{C}$ and $\mathrm{C}_{60}, \mathrm{a}-\mathrm{C} / \mathrm{C}_{60}$ single-junction and two-junction were evaluated using UV-Vis absorption spectroscopy. 
Table 1: Comparison of the Raman Peak Intensity $\left(I_{D} / I_{G}\right)$ in Each Film Sample

\begin{tabular}{|c|c|c|c|}
\hline Structure of two-junction type & $\mathrm{I}_{\mathrm{D}}$ [arb.unit] & $\mathrm{I}_{\mathrm{G}}$ [arb.unit] & $\mathrm{I}_{\mathrm{D}} / \mathrm{I}_{\mathrm{G}}$ \\
\hline $\mathrm{a}-\mathrm{C}: 100 \mathrm{~nm}, \mathrm{C}_{60}: 50 \mathrm{~nm}$ & 0.760 & 1.000 & 0.760 \\
\hline $\mathrm{a}-\mathrm{C}: 100 \mathrm{~nm}, \mathrm{C}_{60}: 10 \mathrm{~nm}, \mathrm{a}-\mathrm{C}: 10 \mathrm{~nm}, \mathrm{C}_{60}: 50 \mathrm{~nm}$ & 0.687 & 0.799 & 0.860 \\
\hline $\mathrm{a}-\mathrm{C}: 100 \mathrm{~nm}, \mathrm{C}_{60}: 20 \mathrm{~nm}, \mathrm{a}-\mathrm{C}: 20 \mathrm{~nm}, \mathrm{C}_{60}: 50 \mathrm{~nm}$ & 0.799 & 0.990 & 0.807 \\
\hline $\mathrm{a}-\mathrm{C}: 100 \mathrm{~nm}, \mathrm{C}_{60}: 30 \mathrm{~nm}, \mathrm{a}-\mathrm{C}: 30 \mathrm{~nm}, \mathrm{C}_{60}: 50 \mathrm{~nm}$ & 0.747 & 0.873 & 0.856 \\
\hline $\mathrm{a}-\mathrm{C}: 100 \mathrm{~nm}, \mathrm{C}_{60}: 40 \mathrm{~nm}, \mathrm{a}-\mathrm{C}: 40 \mathrm{~nm}, \mathrm{C}_{60}: 50 \mathrm{~nm}$ & 0.678 & 0.802 & 0.845 \\
\hline
\end{tabular}

In this analysis, we only applied the sample as described in the Figure 1 excluding the Al electrode.

The reflectance and transmittance of each sample were measured using UV-Vis absorption spectroscopy. The absorbance was calculated from the reflectance and transmittance measurement and assumed that all light to the sample can be reflected, transmitted, and absorbed. The UV-Vis absorption spectra of a-C and $\mathrm{C}_{60}$, a-C/ $\mathrm{C}_{60}$ single and two-junction films are shown in the Figure 4. The absorbance value in Figure 4 also involved the absorption of ITO glass as the sample substrate. Considering to the absorption of the ITO glass, the absorption of a $\mathrm{C}_{60}$ single layer was observed from the ultraviolet range to $600 \mathrm{~nm}$ and the absorption of a-C single layer was observed from the ultraviolet range to $900 \mathrm{~nm}$. As a result, it was found that our films were able to absorb the light in the visible region which is rich of the effective sunlight. Furthermore, in the single and two-junction films, the absorption characteristic showed the combination of absorption in each $\mathrm{C}_{60}$ and a-C. By the result, we noticed that the absorbance value in this work increased due to an increase of film thickness. However, it was found that the prepared sample could

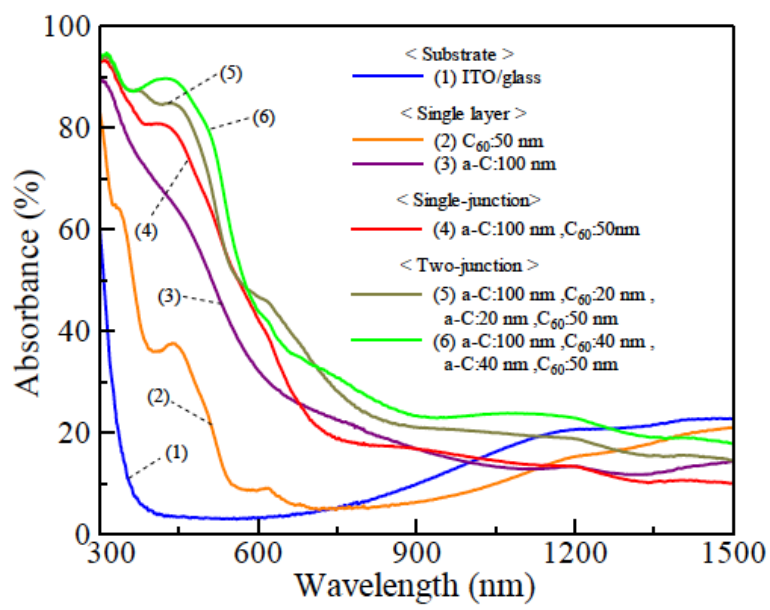

Figure 4: Absorbance of carbon photovoltaic devices with different structures. not absorb the light in the absorption region completely as it was only $80-90 \%$ of maximum visible light could be absorbed in our devices. Therefore, there is a possibility that the absorbance is improved by further increasing of the film thickness.

\subsection{Photovoltaic Properties}

The photovoltaic characteristics of photovoltaic devices using $\mathrm{a}-\mathrm{C}$ and $\mathrm{C}_{60}$ for the single-junction and two-junction structures were evaluated. The singlejunction as the basic structure has total layer thickness of around $150 \mathrm{~nm}$ and two-junction film has different total layer thickness depending on the thickness of inserted layer as shown in the Figure 1.

The J-V characteristics of each sample under AM 1.5 irradiation are shown in Figure 5 and the change of each photovoltaic parameters such as $J_{S C}, V_{O C}, F F$ and PCE due to the changing of film thickness is shown in Figure 6. In Figure 6, the horizontal axis shows each film thickness of a-C and $\mathrm{C}_{60}$ which were inserted between the basic structure, and zero value in the horizontal axis is the result of the single-junction structure. The photovoltaic parameters of all measured samples are listed in the Table 2.

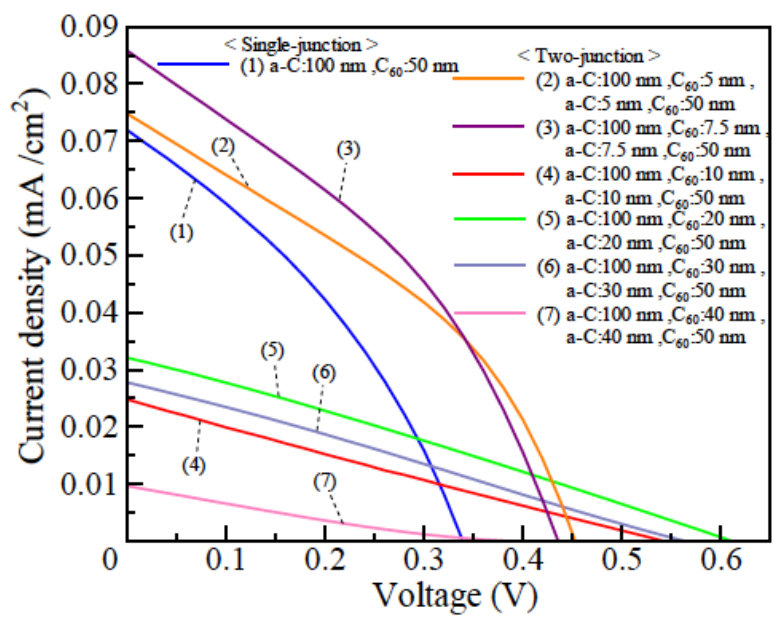

Figure 5: Effect of film thickness on the J-V curve. 

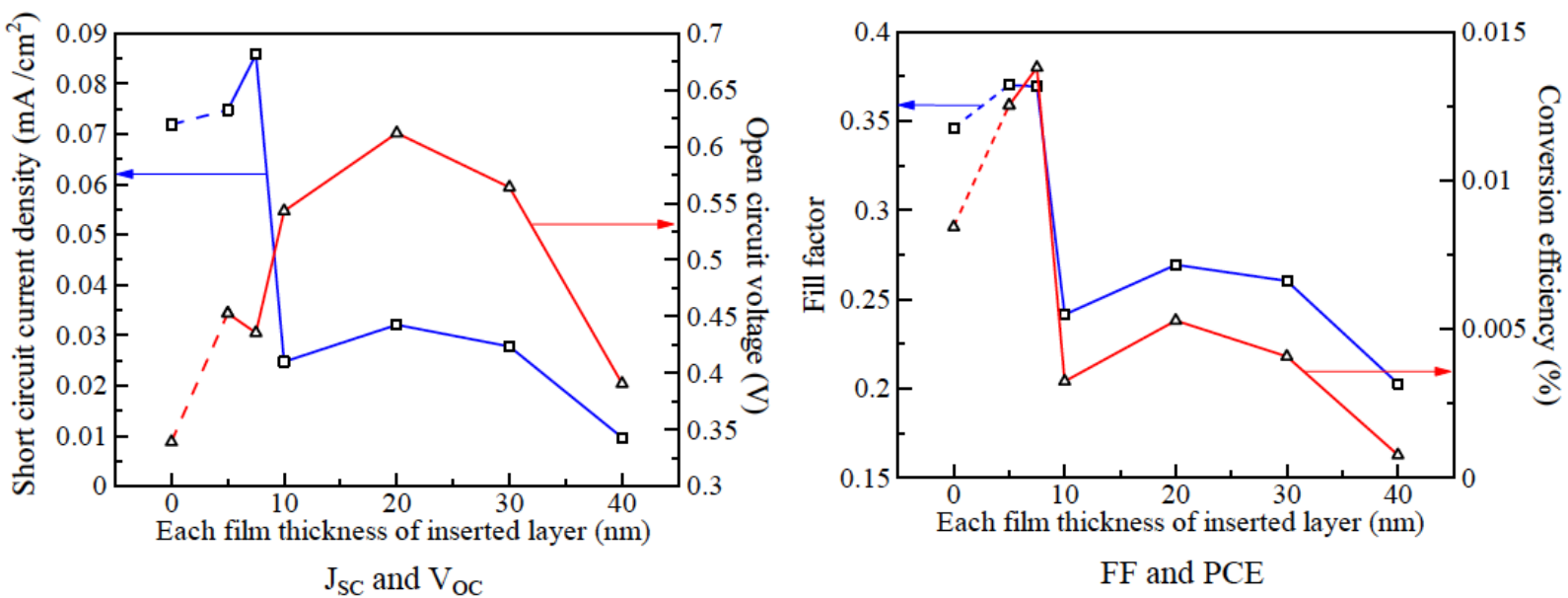

FF and PCE

Figure 6: Effect of film thickness on the photovoltaic performance.

Table 2: Comparison of the Photovoltaic Performance in Each Device Sample

\begin{tabular}{|c|c|c|c|c|c|}
\hline Each film thickness of added film $[\mathrm{nm}]$ & $\mathrm{J}_{\mathrm{SC}}\left[\mathrm{mA} / \mathrm{cm}^{2}\right]$ & $\mathrm{V}_{\mathrm{OC}}[\mathrm{V}]$ & $\mathrm{FF}$ & PCE [\%] & $\mathrm{R}_{\mathrm{S}}\left[\mathrm{k} \Omega \mathrm{cm}^{2}\right]$ \\
\hline 0 (Single-junction) & 0.0719 & 0.339 & 0.346 & 0.0084 & 2.47 \\
\hline 5 & 0.0748 & 0.453 & 0.370 & 0.0125 & 2.26 \\
\hline 7.5 & 0.0858 & 0.435 & 0.369 & 0.0138 & 2.39 \\
\hline 10 & 0.0247 & 0.543 & 0.241 & 0.0032 & 23.09 \\
\hline 20 & 0.0321 & 0.612 & 0.269 & 0.0053 & 17.21 \\
\hline 30 & 0.0278 & 0.564 & 0.260 & 0.0041 & 38.17 \\
\hline 40 & 0.0097 & 0.391 & 0.203 & 0.0008 & 96.15 \\
\hline
\end{tabular}

From the Figure $\mathbf{5}$ and Figure $\mathbf{6}$, it is clearly seen that there is similarity performance between the fabricated single-junction and two-junction photovoltaic device when the thickness of intermediate films in the two-junction device was less than $10 \mathrm{~nm}$. We supposed that the appearance of non-smooth surface in the thinner intermediate layer could be the reason for this case which might results in the contact of thin $\mathrm{C}_{60}$ film and thick $\mathrm{C}_{60}$ layer and also that of thin a-C and thick a$C$ layer. The highest $J_{S C} 0.086 \mathrm{~mA} / \mathrm{cm}^{2}$ was exhibited by the two-junction film with the $7.5 \mathrm{~nm}$ of intermediate layer thickness. It is due to the increasing of interface area due to the non-smooth surface of intermediate layer in the two-junction structure lead to the enhancement in its $J_{S C}$ and $V_{O C}$.

In the two-junction film, $V_{O C}$ value almost doubled when it is compared with the single-junction type, especially for the thickness of intermediate films which was more than $10 \mathrm{~nm}$ in the two-junction type photovoltaic device. This increment might be caused by the tandem structure formation in photovoltaic device which improved their open-circuit voltage. Moreover, these $J_{S C}$ tended to decrease greatly in comparison to the single-junction. In these films, since the tunneljunction layer was not involved in the fabricated twojunction photovoltaic device, it can be still considered that a tandem structure was successfully attained without using the tunnel-junction by considering the $V_{O C}$ increment. The energy level alignment of tandem photovoltaic device is shown in Figure 7 [23]. The constant current flows by the recombination of photogenerated electrons and holes via the defect levels at the thin layer. By observing our photovoltaic parameters, the film thickness in the two-junction type obviously affected its photovoltaic performance, then, we noticed there is the film thickness effect which can maximize some photovoltaic parameters. In this experiment, it was found that both $J_{S C}$ and $V_{O C}$ decrease with increasing the film thickness of inserted layers.

In order to clarify the reason for the performance change due to the film thickness effect, the series resistance $\left(R_{S}\right)$ was calculated from the slope of the J-V curve around $V_{O C}$ and the results of calculated $R_{S}$ are shown in the Figure 8. In this experiment, $R_{S}$ was defined by the J-V characteristics under illumination 


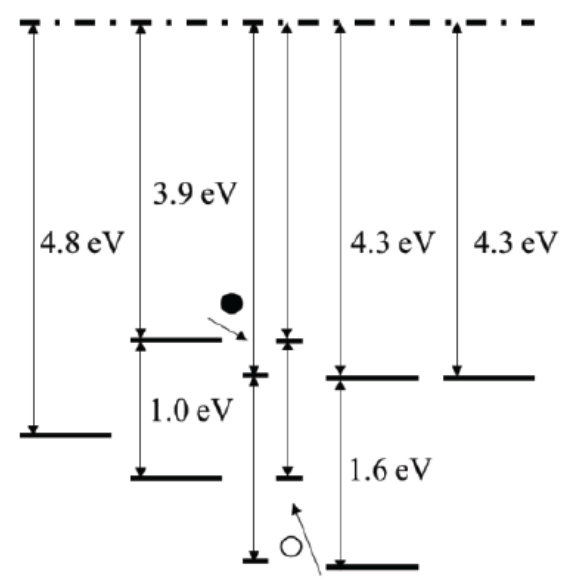

ITO a-C $\quad \mathrm{C}_{60}$ a-C $\quad \mathrm{C}_{60} \quad \mathrm{Al}$

Figure 7: Energy level alignment of two-junction carbon photovoltaic device.

with the current is zero. As shown in Figure $\mathbf{8}$, it is observed that the $R_{S}$ value tends to increase along with increasing of film thickness in the intermediate films. There was a significant increase in the $R_{S}$ value when the intermediate film thickness thicker than $10 \mathrm{~nm}$. This change might be caused by the addition of resistance component on the joint surface due to the formation of two-junction structure. In addition, comparing the $R_{S}$ and $J_{S C}$ values, we noticed that both values are correlated, i.e. $J_{S C}$ decreases and $R_{S}$ increases with film thickness. Hence, it can be viewed that the $J_{S C}$ is greatly influenced by the $R_{S}$. This result is consistent with the idea of the solar cell equivalent circuit and we considered that the value of calculated $R_{s}$ has some reliability.

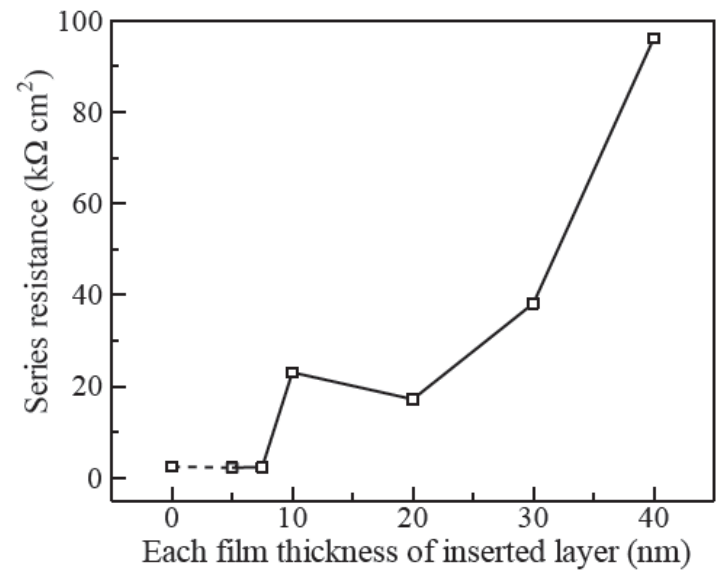

Figure 8: Effect of film thickness on the series resistance.

From the Figure $\mathbf{4}$ and Figure $\mathbf{6}$, there is a possibility that the absorbance is improved by further increasing of the film thickness, even the consequence is the decreasing of $J_{S C}$ when the thickness of intermediate film is $20 \mathrm{~nm}$ or more. Therefore, by increasing the film thickness, the enhancement of $J_{S C}$ due to an increase in absorbance can be expected up to a certain thickness. Nevertheless, when the thickness exceeds to a certain value, it is considered that reduction of $J_{S C}$ occurred owing to the increased $R_{S}$ due to the high resistivity of carbon films. Therefore, to improve $J_{S C}$ furthermore, it is necessary to decrease the resistivity of $\mathrm{a}-\mathrm{C}$ and $\mathrm{C}_{60}$ films.

By forming two-junction type using a-C/ $\mathrm{C}_{60}$, the total value of $R_{S}$ increased, as consequence, the $J_{S C}$ and FF decreased which induced the decreasing of PCE. However, due to the increasing of $V_{O C}$ value in our work, we believe that our two-junction structure has the potential for wider application, for example, for the photoelectric material which requires the high voltage like a sensor. The best $V_{O C}$ in this work is $0.612 \mathrm{~V}$ which is reached by the $20 \mathrm{~nm}$ of intermediate layer in the two-junction tandem device as shown in the Table 2.

\section{CONCLUSION}

In this study, we fabricated both single-junction and two-junction photovoltaic devices which were arranged by a-C and $\mathrm{C}_{60}$ thin films, and their photovoltaic and optical properties were evaluated.

In the two-junction type, when the thickness of the intermediate film was configured for more than $10 \mathrm{~nm}$, the $V_{O C}$ almost doubled compared to the single-junction type. Thus, we considered that the formation of the tandem structure was successfully established. In addition, it was found that the two-junction photovoltaic performance depended on their film thickness. By forming a tandem structure, it could be expected to improve $V_{O C}$, but it could not be expected to improve other parameters due to an increase in resistance component. Therefore, in order to improve the overall performance, we consider that it is necessary to reduce the resistance component of carbon films by impurity doping and defect reduction.

\section{ACKNOWLEDGEMENT}

This work was partly supported by JSPS KAKENHI Grant Number JP16K04960.

\section{REFERENCE}

[1] Lamnatou C and Chemisana D. Photovoltaic/thermal (PVT) systems: A review with emphasis on environmental issues. Renewable Energy 2017; 105: 270-287. https://doi.org/10.1016/j.renene.2016.12.009

[2] Yoshikawa K, Kawasaki H, Yoshida W, Irie T, Konishi K, et al. Silicon heterojunction solar cell with interdigitated back 
contacts for a photoconversion efficiency over $26 \%$. Nature Energy 2017; 2: 17032.

https://doi.org/10.1038/nenergy.2017.32

[3] Wu JL, Hirai Y, Kato T, Sugimoto H, Bermudez V. New world Record efficiency up to $22.9 \%$ for $\mathrm{Cu}(\mathrm{In}, \mathrm{Ga})(\mathrm{Se}, \mathrm{S})_{2}$ thin-film solar cell 7th World Conference on Photovoltaic Energy Conversion (WCPEC-7). IEEE Journal of Photovoltaics 2018; 1-6.

https://doi.org/10.1109/JPHOTOV.2018.2882206

[4] Kayes BM, Nie H, Twist R, Spruytte SG, Reinhardt F, Kizilyalli IC, Higashi GS. $27.6 \%$ conversion efficiency, a new record for single-junction solar cells under 1 sun illumination. 7th IEEE Photovoltaic Specialists Conference. 2011. https://doi.org/10.1109/PVSC.2011.6185831

[5] Britt $\mathrm{J}$ and Ferekides $\mathrm{C}$. Thin-film CdS/CdTe solar cell with 15.8\% efficiency. Applied Physics Letters 1993; 62: 28512852.

https://doi.org/10.1063/1.109629

[6] Mathew S, Yella A, Gao P, Baker RH, Curchod BFE, et al. Dye-sensitized solar cells with $13 \%$ efficiency achieved through the molecular engineering of porphyrin sensitizers. Nature Chem 2014; 6: 242-247. https://doi.org/10.1038/nchem.1861

[7] He Z, Xiao B, Liu F, Wu H, Yang Y, Xiao S, Wang C, Russel TP, Cao Y. Single-junction polymer solar cells with high efficiency and photovoltage. Nature Photonics 2015; 9: 174179. https://doi.org/10.1038/nphoton.2015.6

[8] Park NG, Gratzel M, Miyasaka T, Zhu K and Emery K. Towards stable and commercially available perovskite solar cells. Nature Energy 2016; 1: 16152.

https://doi.org/10.1038/nenergy.2016.152

[9] Sharon M, Mukhopadhyay I, Mukhopadhyay K, A Photoelectrochemical Solar Cells from camphoric p-Carbon semiconductor, Solar Energy Materials and Solar Cells 1997; 45(1): 35-41.

https://doi.org/10.1016/S0927-0248(96)00029-3

[10] Mukhopadhyay K, Mukhopadhyay I, Sharon M, Soga T, Umeno M, Carbon Photovoltaic cell, Carbon 1997; 35(6): 863-864.

https://doi.org/10.1016/S0008-6223(97)80177-7

[11] Krishna KM, Soga T, Mukhopadhyay K, Sharon M, Umeno $\mathrm{M}$, Photovoltaic solar cell from camphoric carbon. A natural Carbon, Solar Energy Materials and Solar cells, 1997; 48(14): 25-33.

https://doi.org/10.1016/S0927-0248(97)00064-0

[12] Yi Y, Coropceanu V and Bredas JL. Exciton-Dissociation and Charge-Recombination Processes in Pentacene/C60 Solar Cells: Theoretical Insight into the Impact of Interface Geometry. J Am Chem Soc 2009; 131(43): 15777-15783. https://doi.org/10.1021/ja905975w

[13] Nasibulin AG, Funde AM, Anoshkin IV, Levitsky IA. Allcarbon nanotube diode and solar cell statistically formed from macroscopic network. Nano Research 2015; 8(9): 28002809. https://doi.org/10.1007/s12274-015-0785-Z

[14] Yin Z, Zhu J, He Q, Cao X, Tan C, et al. Graphene-Based Materials for Solar Cell Applications. Advanced Energy
Materials 2014; 4(1): 1300574. https://doi.org/10.1002/aenm.201300574

[15] Soga T, Kokubu T, Hayashi Y, Jimbo T and Umeno M. Effect of $\mathrm{rf}$ power on the photovoltaic properties of boron-doped amorphous carbon/n-type silicon junction fabricated by plasma enhanced chemical vapor deposition. Thin Solid Films 2005; 482(1-2): 86-89.

https://doi.org/10.1016/j.tsf.2004.11.123

[16] Chhowalla M, Robertson J, chen CW, et al. Influence of ion energy and substrate temperature on the optical and electronic properties of tetrahedral amorphous carbon (ta -C) films. Journal of Applied physics 1997; 81: 139-145. https://doi.org/10.1063/1.364000

[17] Marco ARA, Jonatas FR, Olga B, Edmundo da SB, Lucila C Some optical properties of amorphous hydrogenated carbon thin films prepared by if plasma deposition using methane. Microelectronics Journal 2001; 32: 783-786. https://doi.org/10.1016/S0026-2692(01)00046-5

[18] Soga T, Kondoh T, Kishi N and Hayashi $\mathrm{Y}$. Photovoltaic properties of an amorphous carbon/fullerene junction. Carbon 2013; 60: 1-4.

https://doi.org/10.1016/j.carbon.2013.02.050

[19] Konofaos $\mathrm{N}$ and Thomas C.B. Characterization of heterojunction devices constructed by amorphous diamondlike films on silicon. J Appl Phys 1996; 81: 62386245.

https://doi.org/10.1063/1.364412

[20] Schwabegger G, Ullaha M, Irimia-Vladu M, Baumgartner M, Kanbur Y, Ahmed R, Stadler P, Bauer S, Sariciftci N. S, Sittera $\mathrm{H}$. High mobility, low voltage operating $\mathrm{C}_{60}$ based $\mathrm{n}$ type organic field effect transistors. Synthetic Metals 2011; 161: 2058-2062.

https://doi.org/10.1016/j.synthmet.2011.06.042

[21] Rupesinghe NL, Cole RJ, Chhowalla M, Amaratunga GAJ, Weightman P. Tetrahedral amorphous carbon-silicon heterojunction band energy offsets. Diamond Relat Mater 2000; 9: 1148-1153.

https://doi.org/10.1016/S0925-9635(00)00195-3

[22] Kojima N, Yamaguchi M, Ishikawa N. Analysis of photovoltaic properties of $\mathrm{C}_{60}-\mathrm{Si}$ heterojunction solar cells. Jpn J Appl Phys 2000; 39: 1176-1179. https://doi.org/10.1143/JJAP.39.1176

[23] Soga T, Nakagaki T, Kato $S$ and Kishi N. Effect of Sublimation Temperature on the Photovoltaic Properties of Amorphous Carbon Thin Films from fullerene. Journal of Solar Energy Research Updates, 2018: 5: 1-6 http://dx.doi.org/10.15377/2410-2199.2018.05.1

[24] Dresselhaus MS, Dresselhaus G, Eklund PC. Science of fullerenes and carbon nanotubes. Academic Press; 1996. https://doi.org/10.1002/adma.19970091518

[25] Ferrari AC and Robertson J. Interpretation of Raman spectra of disordered and amorphous carbon. Phys Rev 2000; B 61(20): 14095-14107. https://doi.org/10.1103/PhysRevB.61.14095

[26] Robertson J and O'Reilly EP. Electronic and atomic structure of amorphous carbon. Phys Rev 1987; B 35(6): 2946-2957. https://doi.org/10.1103/PhysRevB.35.2946 